\section{Eldre med depresjon - oppfølging over tre år}

\author{
ORIGINALARTIKKEL
}

\section{TOM BORZA}

E-post: tom.borza@sykehuset-innlandet.no Forskningssenter for aldersrelatert funksjonssvikt og sykdom Sykehuset Innlandet, Sanderud Han har bidratt med analyser, datainnsamling og -tolkning samt manusutarbeiding, revisjon og godkjenning av siste versjon.

Tom Borza er ph.d., overlege og spesialist i psykiatri.

Forfatteren har fylt ut ICMJE-skjemaet og oppgir ingen interessekonflikter.

\section{KNUT ENGEDAL}

Nasjonal kompetansetjeneste for aldring og helse Sykehuset Vestfold Han har bidratt med idé til studien, prosjektledelse, datainnsamling og -tolkning samt manusutarbeiding, revisjon og godkjenning av siste versjon.

Knut Engedal er dr.med., spesialist i psykiatri og professor emeritus.

Forfatteren har fylt ut ICMJE-skjemaet og oppgir ingen interessekonflikter.

\section{SVERRE BERGH}

Forskningssenter for aldersrelatert funksjonssvikt og sykdom Sykehuset Innlandet, Sanderud og

Nasjonal kompetansetjeneste for aldring og helse Sykehuset Vestfold, Tønsberg Han har bidratt med datainnsamling og -tolkning samt manusutarbeiding, revisjon og godkjenning av siste versjon Sverre Bergh er ph.d., spesialist i psykiatri og forskningsleder. Forfatteren har fylt ut ICMJE-skjemaet og oppgir ingen interessekonflikter.

\section{GEIR SELBAEK}

Nasjonal kompetansetjeneste for aldring og helse Sykehuset Vestfold, Tønsberg

og

Det medisinske fakultet

Universitetet i Oslo

Han har bidratt med idé til studien, prosjektledelse, datainnsamling og -tolkning samt manusutarbeiding, revisjon og godkjenning av siste versjon. Geir Selbæk er ph.d., spesialist i psykiatri, forskningssjef og professor. Forfatteren har fylt ut ICMJE-skjemaet og oppgir ingen interessekonflikter. 


\section{BAKGRUNN}

Forekomsten av depresjon hos eldre på diagnosenivå er 1-5\%. Depresjon hos eldre kan være kronisk og er assosiert med økt risiko for demensutvikling. Det foreligger ingen norske longitudinelle undersøkelser av depresjon hos eldre.

\section{MATERIALE OG METODE}

Vi har utført en multisenter, longitudinell observasjonsstudie av 160 pasienter $\geq 60$ år behandlet for depresjon i norske alderspsykiatriske sengeavdelinger. Pasientene har vært fulgt med fire kartlegginger over en treårsperiode.

\section{RESULTATER}

Av de 131 som fullførte studien, var 24 (18,3\%) uten depresjon og depressive symptomer ved oppfølgingstidspunktene etter innleggelsen, 55 (42,0 \%) hadde vist depressive symptomer og $51(38,9 \%)$ hadde hatt minst ett alvorlig tilbakefall eller vært kontinuerlig syke av en depresjonstilstand. Andelen personer med demens $ø$ kte fra 14 av 160 ( $8,8 \%)$ ved studiestart til 40 av 131 (30,5\%) etter tre år.

\section{FORTOLKNING}

Eldre med depresjon behandlet i spesialisthelsetjenesten for alderspsykiatri har en ugunstig prognose med tanke på forløp av depresjon og utvikling av demens over en treårsperiode.

Forekomsten av depresjon på diagnosenivå hos eldre (oftest definert som $\geq 60$ år eller $\geq 65$ år) er ifølge ulike studier angitt til å være 1-5\%(1). Depressive symptomer som i sum ikke tilfredsstiller depresjon på diagnosenivå kan forekomme opptil 2-3 ganger hyppigere enn depresjon. Symptomene kan like fullt ha klinisk betydning i form av redusert livskvalitet, redusert sosial funksjon og $ø$ kt risiko for å utvikle depresjon (2). Blant eldre som er innlagt på sykehus eller sykehjem, er forekomsten av depresjonstilstander (depresjon på diagnosenivå og depressive symptomer) høyere enn for hjemmeboende (3).

Ratene for respons og remisjon ved depressive episoder hos eldre og yngre voksne er like, men risikoen for tilbakefall er større hos eldre (4). I tillegg er det vist at depresjon hos eldre har tendens til å bli kronisk, fører til problemer med å utføre funksjoner i dagliglivet og er assosiert med $ø \mathrm{kt}$ risiko for utvikling av demens og tidligere $\mathrm{d} ø \mathrm{~d}$ sammenlignet med eldre uten depresjon $(1,5,6)$. Overlappende symptomer på demens og depresjon hos eldre kan være en differensialdiagnostisk utfordring $(6,7)$. I tillegg til negative kliniske konsekvenser kan depresjonstilstander hos eldre føre til store kostnader for samfunnet $(1,8)$.

Alderspsykiatriske sengeavdelinger tar typisk imot eldre med alvorlig grad av depresjon, som ikke kan ta vare på seg selv, med høy selvmordsfare eller stor grad av samsykelighet. Det foreligger ingen systematiske longitudinelle unders $\varnothing$ kelser av depresjon hos eldre i Norge, og det er få slike undersøkelser fra Norden. Vi har derfor utført en multisenter, longitudinell observasjonsstudie av eldre pasienter behandlet for depresjon i norske alderspsykiatriske avdelinger, Prognosis of Depression in the Elderly (PRODE), for å unders $\emptyset$ ke prognosen med hensyn til depresjonsforløp, demensutvikling og funksjon i dagliglivet i en tre års oppfølgingsperiode $(9,10)$.

\section{Materiale og metode}

I PRODE-studien inkluderte vi pasienter 60 år og eldre henvist til innleggelse i alderspsykiatrisk spesialisthelsetjeneste grunnet depresjon. Pasienter med alvorlig grad av demens eller annen sykdom som gjorde at de ikke kunne kommunisere verbalt og pasienter med kort forventet levetid pga. somatisk sykdom, ble ikke forespurt. Ni alderspsykiatriske sengeavdelinger (Oslo universitetssykehus, Ullevål og Aker; 
Diakonhjemmet Sykehus; Vestre Viken; Sykehuset Innlandet, Sanderud og Reinsvoll; Stavanger universitetssjukehus; St. Olavs Hospital og Haukeland universitetssjukehus) rekrutterte deltagere i tidsrommet 1.12.2009-1.1.2013.

Helsearbeidere ved de ulike studiesentrene innhentet klinisk og demografisk informasjon ved bruk av en standardisert protokoll ved innleggelse på og ved utskriving fra alderspsykiatrisk avdeling. Det ble avholdt opplæringsmøter i bruk av aktuelle måleskalaer før oppstart av studien og to ganger årlig i studieperioden. Psykiatere eller psykologspesialister diagnostiserte demens og depresjon i henhold til kriteriene i diagnoseklassifikasjonssystemet ICD-10 (11). Alvorlighetsgrad av depressive symptomer ble vurdert med Montgomery and Aasberg Depression Rating Scale (MADRS) (12) og Cornells skala for depresjon ved demens (CSDD) (13). Førstnevnte inneholder ti spørsmål til pasienten om depressive symptomer som hvert vurderes på en skala o-6 (totalskår o-6o), hvor høyere skår indikerer alvorligere symptom. Cornells skala inkluderer informasjon fra pårørende eller helsearbeidere og inneholder 19 depressive symptomer som hvert skåres o-2 etter alvorlighetsgrad (totalskår 0-38). Jo høyere skår, jo mer alvorlige symptomer. Kognisjon ble vurdert med Mini Mental Status (MMS) som har skår o-3o. Her indikerer høyere skår bedre kognitiv funksjon (14). Instrumentelle funksjoner i dagliglivets gjøremål (I-ADL) ble vurdert med Lawton \& Brodys skala (15). Vi summerte skårene for de åtte ulike IADL-funksjonene i skalaen (totalskår 8-31), og lavere skår indikerte bedre funksjon. Legene vurderte somatisk helse med General Medical Health Rating Scale (GMHR) (16), en gradert skala (svært god/god/nokså god/dårlig) basert på vurdering av medisinske diagnoser og antall medisiner. I analysene ble skårene dikotomisert til svært god/god og nokså god/dårlig.

Pasientene fikk den behandlingen som var vanlig praksis ved studiestedene. 41 av 160 $(25,6 \%)$ fikk elektrokonvulsiv behandling, mens alle 160 fikk en eller annen form for samtalebehandling. Ved utskrivning brukte 134 av 160 (83,8\%) antidepressiver og 42 av 160 $(26,3 \%)$ antipsykotika. Tilsvarende tall ved innleggelse (inklusjon i studien) var henholdsvis 114 av 160 ( $71,3 \%)$ og 38 av 160 ( $23,8 \%)$ (9).

Ett år etter inklusjon ble pasientene fulgt opp med en klinisk undersøkelse ved studiesentrene, og det ble innhentet tilsvarende data som ved innleggelsen (tabell 1). Resultater fra innleggelsen og ett års oppfølging er publisert tidligere $(9,10)$.

\section{Tabell 1}

Data som ble innhentet med måleinstrumenter ved de ulike måletidspunktene i studien. $\mathrm{T}_{\mathrm{o}}$ $=$ ved inklusjon i studien, $\mathrm{T}_{1}=$ ved utskrivning fra alderspsykiatrisk avdeling, $\mathrm{T}_{2}=$ oppfølgingsundersøkelse etter ett år, $\mathrm{T}_{3}=$ oppfølgingsundersøkelse etter tre år.

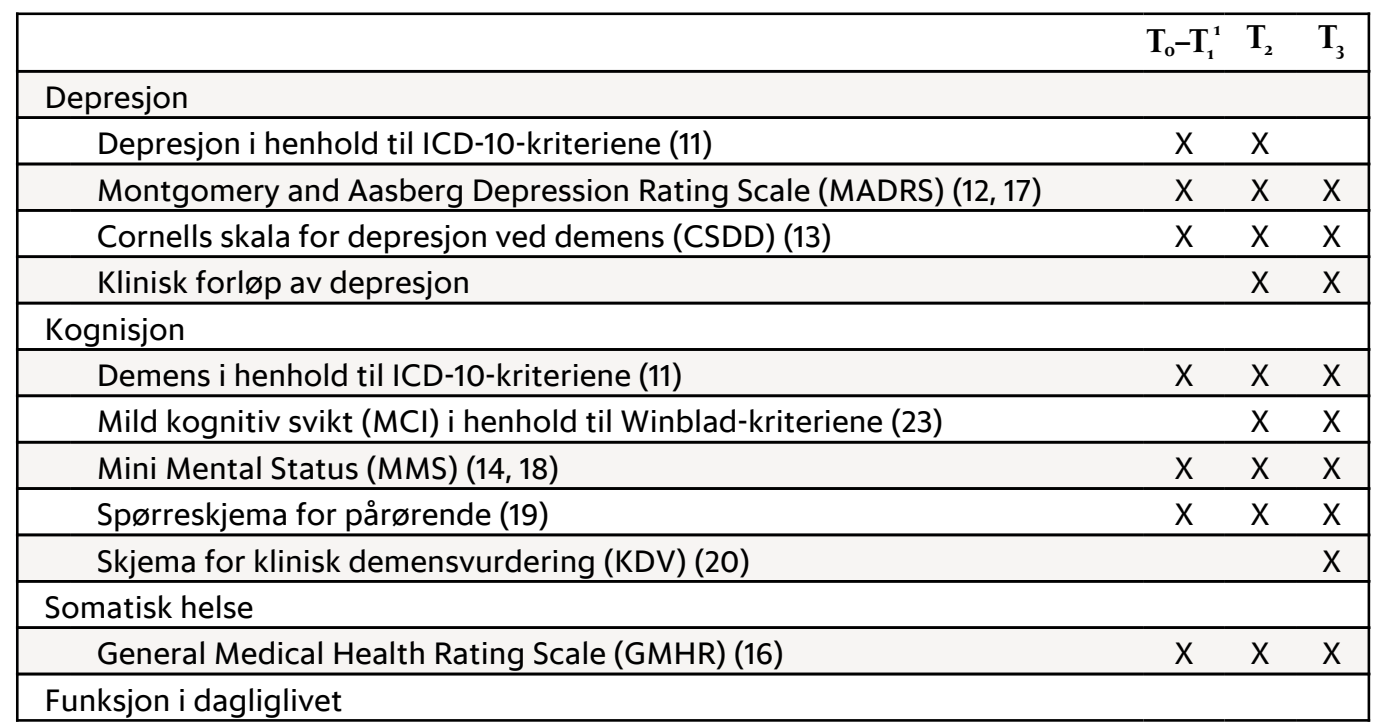




\begin{tabular}{|lccc|}
\hline & $\mathbf{T}_{\mathbf{0}}-\mathbf{T}_{1}^{1}$ & $\mathbf{T}_{2}$ & $\mathbf{T}_{3}$ \\
\hline $\begin{array}{l}\text { Lawton \& Brodys skala for instrumentelle aktiviteter i dagliglivets } \\
\text { gjøremål (I-ADL) (15) }\end{array}$ & $\mathrm{X}$ & $\mathrm{X}$ & $\mathrm{X}$ \\
\hline
\end{tabular}

${ }^{1}$ I løpet av innleggelsen i alderspsykiatrisk avdeling

\section{OPPFØLGINGSUNDERSØKELSE ETTER TRE ̊R}

Tre år etter inklusjon ble pasientene og eventuelle pårørende samt helsearbeidere fra sykehjem eller hjemmebasert omsorg der det var aktuelt, kontaktet med telefonundersøkelser administrert fra Sykehuset Innlandet, Sanderud. Vi innhentet informasjon om depresjonsforløp, kognisjon, somatisk helse (GMHR) og funksjon (Lawton \& Brodys skala for I-ADL) i intervjuene. Intervjuerne vurderte skjønnsmessig hvilken informasjon som var mest valid hvis det ikke var fullt samsvar mellom samme type informasjon fra pasient og pårørende/helsearbeidere. Pasientene ble spurt om hvordan de hadde opplevd depresjonsforløpet (frisk av depresjon/tilbakefall av depresjon/kontinuerlig syk av depresjon) etter ettårsoppfølgingen. De ble intervjuet med en validert telefonversjon av MADRS-skalaen (17) $(\mathrm{n}=105)$. I tillegg fylte pårørende og/eller helsearbeidere ut Cornells skala for depresjon ved demens $(n=106)$.

Pasientene $(\mathrm{n}=95)$ gjennomgikk en validert telefonversjon av Mini Mental Status (MMS) (18). Ytterligere 18 pasienter med en helsetilstand som ikke gjorde det mulig å gjennomføre denne testen via telefon, gjennomgikk en tradisjonell MMS-test (14) i primærhelsetjenesten. Kognitiv endring over tid ble målt på Spørreskjema for pårørende (19), og Skjema for klinisk demensvurdering (20) ble fylt ut av intervjuer på bakgrunn av all innhentet informasjon om kognisjon fra telefonintervjuene. Spørreskjema for pårørende inneholder 16 spørsmål om kognitive endringer over tid, i denne studien over de siste to årene. I Skjema for klinisk demensvurdering evalueres kognisjon og funksjon ut fra tilgjengelig informasjon om hukommelse, orienteringsevne, vurderingsevne, samfunnsaktiviteter, hjem, fritidsinteresser og egenomsorg.

Med bakgrunn i depresjonsdata innsamlet i studien ved ett- og treårsoppfølgingene klassifiserte vi depresjonsforløpet over tre år i kategoriene gunstig/mindre gunstig/ugunstig/lot seg ikke klassifisere. I kategorien ugunstig forløp var pasienter som hadde utført et selvmordsforsøk, hadde opplevd minst ett tilbakefall som medførte innleggelse på sykehus, eller som ble vurdert av intervjuer som kontinuerlig syk av en depresjonstilstand. I mindre gunstig forløp var pasienter som hadde vist depressive symptomer (MADRS > 9 (21) og/eller CSDD > 8 (22)), men ikke tilfredsstilte kriteriene for gunstig eller ugunstig forløp. Gunstig forløp var når pasienter var uten tilbakefall av depresjon eller depressive symptomer (MADRS > 9 og/eller CSDD > 8) i oppfølgingstiden.

Tre av forfatterne, alle psykiatere med doktorgrad, brukte all tilgjengelig informasjon fra undersøkelsene til uavhengig av hverandre å klassifisere kognisjon ved treårsundersøkelsen til kategoriene uten kognitiv svikt, mild kognitiv svikt i henhold til Winblads kriterier (23) og demens i henhold til ICD-10 (11). De tre var initialt enige om klassifiseringen av kognitiv status for 102 av 131 pasienter $(77,9 \%)$ og avholdt et konsensusmøte for å klassifisere de 29 pasientene $(22,1 \%)$ hvor det ikke var samsvar.

\section{ETIKK}

Pasientene og pårørende fikk muntlig og skriftlig informasjon om studien og ga skriftlig samtykke til deltagelse. For pasienter uten samtykkekompetanse ga nærmeste pårørende skriftlig samtykke på vegne av pasienten. Studien er godkjent i Regional etisk komité Sør$\emptyset$ st (2009/1774), av personvernombudet ved Oslo universitetssykehus og er registrert i ClinicalTrials.gov (NCTo1952366).

\section{STATISTIKK}

Uavhengig og paret t-test ble anvendt for kontinuerlige data og khikvadrattest og McNemars test for kategoriske data. Alle analysene er gjort med SPSS versjon 25. 


\section{Resultater}

Ved seks av de ni deltagende studiesentrene kunne det gjøres rede for kjønn og alder på pasienter som takket nei til deltagelse i studien. Blant disse seks studiesentrene ble 174 aktuelle pasienter forespurt, og 38 takket nei. Det var ingen forskjell i kjønn eller alder på de som takket ja eller nei til å delta i studien (9).

Figur 1 viser pasientflyt i studien, og tabell 2 viser karakteristika for pasientene ved inklusjon i studien $\left(T_{0}\right)$, utskrivning fra alderspsykiatrisk avdeling $\left(T_{1}\right)$ og tre år etter inklusjon $\left(\mathrm{T}_{3}\right)$. Sammenlignet med de 29 pasientene som ikke fullførte studien, var de 131 som fullførte $T_{3}$ yngre $(\mathrm{p}=0,028)$, hadde høyere MMS-skår ( $\left.\mathrm{p}<\mathrm{o}, 001\right)$, høyere MADRS-skår ( $\mathrm{p}$ $=0,034)$, oftere svært god/god somatisk helse $(p=0,001)$ ved $T_{0}$ og sjeldnere demens ved $T_{1}(p$ $=0,004)$.

Ved T3 var 21 pasienter døde (figur 1). Det var ingen kjønnsforskjell i dødelighet $(\mathrm{p}=0,480)$.

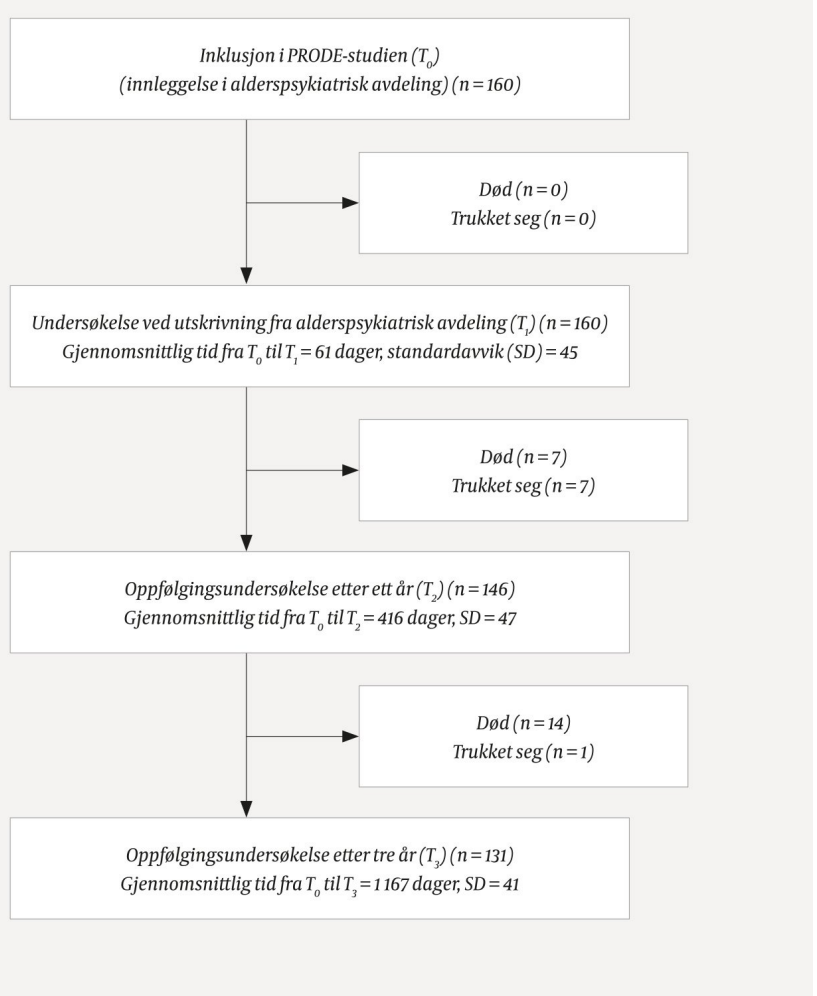

Figur 1 Flytdiagram for utvalget i studien Prognosis of Depression in the Elderly (PRODE) fra inklusjon i studien til oppfølgingsundersøkelse tre år etter.

\section{Tabell 2}

Demografiske og kliniske data for studieutvalget ved innleggelse i alderspsykiatrisk avdeling og etter tre år. Data er presentert med gjeldende verdier ved måletidspunktene. $T_{0}$ $=$ ved inklusjon i studien, $\mathrm{T}_{1}=$ ved utskrivning fra alderspsykiatrisk avdeling, $\mathrm{T}_{3}=$ oppfølgingsundersøkelse etter tre år.

\begin{tabular}{|c|c|c|c|}
\hline & $\begin{array}{c}T_{0} \\
(n=160)\end{array}$ & $\begin{array}{c}T_{1} \\
(n=160)\end{array}$ & $\begin{array}{c}\mathrm{T}_{3} \\
(\mathbf{n}=\mathbf{1 3 1})\end{array}$ \\
\hline \multicolumn{4}{|l|}{ Demografi } \\
\hline Alder i år, gjennomsnitt (standardavvik, SD) & $76,1(6,8)$ & & $78,8(6,4)$ \\
\hline Andel kvinner & $72,5 \%$ & & $73,9 \%$ \\
\hline $\begin{array}{l}\text { År med utdanning, gjennomsnitt }(S D)\left(n=151 \text { ved } T_{0}, n=\right. \\
\left.124 \text { ved } T_{3}\right)\end{array}$ & $10,0(3,0)$ & & $10,0(3,0)$ \\
\hline
\end{tabular}




\begin{tabular}{|c|c|c|c|}
\hline & $\begin{array}{c}T_{0} \\
(n=160)\end{array}$ & $\begin{array}{c}T_{1} \\
(n=160)\end{array}$ & $\begin{array}{c}T_{3} \\
(n=131)\end{array}$ \\
\hline \multicolumn{4}{|l|}{ Sivilstatus } \\
\hline Gift/samboer & $40,0 \%$ & & $38,9 \%$ \\
\hline Enke/enkemann/skilt/enslig & $60,0 \%$ & & $61,1 \%$ \\
\hline \multicolumn{4}{|l|}{ Depresjon } \\
\hline Depresjon for første gang ved inklusjon & $30,6 \%$ & & \\
\hline Bipolar sykdom i henhold til ICD-10 & $6,3 \%$ & & \\
\hline Psykotisk depresjon i henhold til ICD-10 & $9,4 \%$ & & \\
\hline \multicolumn{4}{|l|}{ Alder ved første depresjon i kategorier $(n=157$ ved To $)$} \\
\hline$<60$ år & $49,0 \%$ & & \\
\hline$\geq 60$ år & $51,0 \%$ & & \\
\hline MADRS'-skår, gjennomsnitt (SD) $(n=157$ ved To $)$ & $26,1(8,6)$ & & \\
\hline \multicolumn{4}{|l|}{ Kognisjon } \\
\hline $\begin{array}{l}\text { Mini Mental Status (MMS), gjennomsnitt (SD) ( } n=156 \\
\text { ved To) }\end{array}$ & $25,9(3,6)$ & & \\
\hline Demensdiagnose i henhold til ICD-10 & & $8,8 \%$ & $30,5 \%$ \\
\hline Mild kognitiv svikt (MCI) & & & $33,6 \%$ \\
\hline \multicolumn{4}{|l|}{ Somatisk helse } \\
\hline \multicolumn{4}{|l|}{ GMHR²-kategorier } \\
\hline Svært god/god & $48,1 \%$ & & $27,5 \%$ \\
\hline Nokså god/dårlig & $51,9 \%$ & & $72,5 \%$ \\
\hline \multicolumn{4}{|l|}{ Funksjon i dagliglivet } \\
\hline $\begin{array}{l}\text { I-ADL }- \text {-skår, gjennomsnitt (SD) }\left(n=136 \text { ved } T_{0}, n=117 \text { ved }\right. \\
\left.T_{3}\right)\end{array}$ & $15,3(6,1)$ & & $17,9(7,9)$ \\
\hline Sykehjemsbeboer & $1,3 \%$ & & $15,3 \%$ \\
\hline
\end{tabular}

${ }^{1}$ MADRS = Montgomery and Aasberg Depression Rating Scale

${ }^{2} \mathrm{GMHR}=$ General Medical Health Rating Scale

${ }^{3}$ Lawton \& Brodys skala for instrumentelle aktiviteter i dagliglivets gjøremål

\section{STATUS ETTER TRE $̊ R$}

Ved $\mathrm{T}_{3}$, sammenlignet med $\mathrm{T}_{0}$, hadde en større andel av pasientene nokså god/dårlig somatisk helse ( $\mathrm{p}<\mathrm{o}, \mathrm{o01})$, en større andel bodde i sykehjem ( $\mathrm{p}<0,001)$, og vi fant høyere IADL-skår ( $\mathrm{p}=0,001$ for $\mathrm{n}=103$ ved målinger på begge tidspunkter) (tabell 2 ). En større andel hadde fått demensdiagnose $(\mathrm{p}<0,001)$. Depresjonsforløpet over tre år viste at $24 \mathrm{av}$ 131 pasienter (18,3\%) var i kategorien gunstig, 55 av 131 (42,0 \%) i mindre gunstig, 51 av 131 (38,9\%) i ugunstig, og 1 (o,8 \%) lot seg ikke klassifisere.

\section{Diskusjon}

Denne undersøkelsen viser at eldre med depresjon behandlet i norsk alderspsykiatrisk spesialisthelsetjeneste har en ugunstig prognose med tanke på tilbakefall av depresjon og vedvarende depressive symptomer. Av de 131 pasientene som ble fulgt opp i tre år, hadde kun $24(18,3 \%)$ vært fri for depresjon og depressive symptomer. I tillegg viser studien at en større andel av pasientene hadde demens etter tre år sammenlignet med ved studiestart, henholdsvis 40 av 131 (30,5\%) og 14 av 160 ( $8,8 \%$ ).

Våre resultater rundt depresjonsforløpet samsvarer med funn i internasjonale undersøkelser, men forskjeller i pasientutvalg, bruk av ulike definisjoner for depresjon og ulik oppfølgingstid gjør direkte sammenligninger vanskelig $(5,24)$. Vi definerte at tilbakefall av depresjon i oppfølgingsperioden medførte et ugunstig forløp selv om pasienten ble frisk etter tilbakefall. Andre studier har definert dette annerledes, noe som delvis kan forklare at forholdvis mange ble klassifisert i den dårligste forløpskategorien i vår studie. Mange tidligere studier har ekskludert pasienter med demens, mens denne studien er en av få longitudinelle observasjonsstudier som også har inkludert pasienter 
med demens $(1,5)$. Dette kan ha påvirket resultatene, da demens og depresjon har overlappende symptomer.

Pasientutvalget i vår studie var en selektert gruppe og omfattet mange med alvorlig depresjon og multimorbiditet. Resultatene er således ikke overførbare til alle eldre med depresjon. I en nederlandsk forløpsundersøkelse over to år av 285 pasienter $\geq 60$ år med depresjon uten demens rekruttert fra både helseinstitusjoner og allmennpraksis fant man at $61 \%$ hadde depressive symptomer av mer eller mindre kronisk karakter, $20 \%$ intermitterende symptomer og $19 \%$ forble friske etter den initiale behandlingen (24). Videre viste studien at $56 \%$ av pasientene som ikke tilfredsstilte diagnosekriteriene for depresjon ved toårsoppfølgingsundersøkelsen, hadde depressive symptomer. Studien inkluderte et annet pasientutvalg og brukte andre kartleggingsskjemaer enn vår studie, men viser også at depresjonstilstander hos eldre ofte er kroniske.

Depresjon hos eldre kan være forbundet med demens på flere måter (6). Depresjon tidligere i livet kan være en risikofaktor for demens, depresjon kan være prodromalsymptom for demens eller begge tilstander kan forekomme samtidig $(1,6)$. Vi fant at en større andel av pasientene hadde demens ved treårsoppfølgingen sammenlignet med undersøkelsen tre år tidligere, henholdsvis 30,5\% og 8,8\%. Funnene våre er i tråd med undersøkelser som beskriver at depresjon hos eldre kan være prodromalsymptom for demens (25). Depresjonssykdommen kan videre ha fremskyndet/forverret en pågående preklinisk demenstilstand, slik en har funnet $i$ andre studier (6). Mer alvorlig grad av depresjon og persisterende depressive symptomer ser spesielt ut til å være forbundet med $ø$ kt risiko for demensutvikling $(6,25)$. Ved treårsoppfølgingen hadde $64,1 \%$ av pasientene enten demens eller mild kognitiv svikt. Dette viser at ulike grader av kognitiv svikt er vanlig $\mathrm{i}$ depresjonsforløpet hos eldre. Studier har vist at symptomer på kognitiv svikt ved depresjon hos eldre er mer persisterende enn tidligere antatt (1).

\section{STYRKER OG SVAKHETER I STUDIEN}

En svakhet ved studien er at vi ikke hadde en kontrollgruppe med eldre personer uten depresjon. Videre er det en svakhet at vi endret prosedyre for datainnsamling, fra personlige undersøkelser til telefonintervju ved treårsoppfølgingen. Dette kan ha påvirket resultatene, men det er vanskelig å si i hvilken retning med tanke på demensutvikling og depresjonsforløp. Depresjonssymptomer kan fluktuere og burde ha blitt vurdert oftere under oppfølgingstiden. Flere forskjellige helsearbeidere var involvert i vurderingene av pasientene, og vurderingene kan derfor være ulike. For å få en mer lik vurdering av pasientenes symptomer avholdt vi derfor opplæring før studiestart og to ganger i året underveis.

Studiedeltagerne hadde høy samsykelighet og var en selektert gruppe av inneliggende pasienter med depresjon, som gjør at resultatene ikke er overførbare til alle eldre med depresjon. Noen demografiske og kliniske variabler manglet gyldige verdier. En styrke ved studien er at vi benyttet få eksklusjonskriterier. En annen styrke er at vi kan gjøre rede for alle pasientene ved treårsoppfølgingen, og kun åtte av 160 trakk seg underveis (24). Vi har videre brukt validerte måleinstrumenter i et longitudinelt design. Funnene er tydelige og robuste.

\section{Konklusjon}

Vår undersøkelse viser at eldre med depresjon behandlet i alderspsykiatrisk spesialisthelsetjeneste har en ugunstig prognose med tanke på forløp av depresjon og utvikling av demens over en treårsperiode. Leger og andre helsearbeidere som er i kontakt med tilsvarende eldre pasienter med depresjon bør være oppmerksomme på risiko for tilbakefall og demensutvikling. 


\section{HOVEDFUNN}

En femdel av eldre pasienter innlagt i alderspsykiatrisk spesialisthelsetjeneste med depresjon hadde ved oppfølgingsundersøkelse etter tre år vært uten tilbakefall av depresjon eller depressive symptomer.

Forekomsten av demens blant eldre med depresjon innlagt i spesialisthelsetjenesten ble tredoblet i løpet av tre år.

\section{LITTERATUR:}

1. Thomas A. Depression in older people. I: Dening T, Thomas A, red. Oxford Textbook of Old Age Psychiatry. 2. utg. Oxford: Oxford University Press, 2013: 544-69.

2. Meeks TW, Vahia IV, Lavretsky H et al. A tune in "a minor" can "b major”: a review of epidemiology, illness course, and public health implications of subthreshold depression in older adults. J Affect Disord 2011; 129:126-42. [PubMed][CrossRef]

3. Rosenvinge BH, Rosenvinge JH. Forekomst av depresjon hos eldre-systematisk oversikt over 55 prevalensstudier fra 1990-2001. Tidsskr Nor Laegeforen 2003; 123: 928-9. [PubMed]

4. Mitchell AJ, Subramaniam H. Prognosis of depression in old age compared to middle age: a systematic review of comparative studies. Am J Psychiatry 2005; 162: 1588-601. [PubMed][CrossRef]

5. Cole MG, Bellavance F. The prognosis of depression in old age. Am J Geriatr Psychiatry 1997; 5: 4-14. [PubMed][CrossRef]

6. Bennett S, Thomas AJ. Depression and dementia: cause, consequence or coincidence? Maturitas 2014; 79:184-9o. [PubMed][CrossRef]

7. Bystad M, Pettersen K, Grønli OK. Depresjon eller demens av Alzheimers type? Tidsskr Nor Legeforen 2014; 134: 525-8. [PubMed][CrossRef]

8. Tollånes MC, Knudsen AK, Vollset SE et al. Sykdomsbyrden i Norge i 2016. Tidsskr Nor Legeforen 2018; 138. doi: 10.4045/tidsskr.18.0274. [PubMed][CrossRef]

9. Borza T, Engedal K, Bergh S et al. The course of depression in late life as measured by the Montgomery and Asberg Depression Rating Scale in an observational study of hospitalized patients. BMC Psychiatry 2015; 15: 191. [PubMed][CrossRef]

10. Borza T, Engedal K, Bergh S et al. Trajectories of depression in late life: A 1-year follow-up study. Dement Geriatr Cogn Disord 2017; 43: 180-92. [PubMed][CrossRef]

11. The ICD-10 Classification of Mental and Behavioural Disorders - Diagnostic Criteria for Research. Geneva: World Health Organization, 1993.

12. Montgomery SA, Asberg M. A new depression scale designed to be sensitive to change. $\mathrm{Br} J$ Psychiatry 1979; 134:382-9. [PubMed][CrossRef]

13. Alexopoulos GS, Abrams RC, Young RC et al. Cornell Scale for Depression in Dementia. Biol Psychiatry 1988; 23: 271-84. [PubMed][CrossRef]

14. Folstein MF, Folstein SE, McHugh PR. "Mini-mental state”. A practical method for grading the cognitive state of patients for the clinician. J Psychiatr Res 1975; 12: 189-98. [PubMed][CrossRef]

15. Lawton MP, Brody EM. Assessment of older people: self-maintaining and instrumental activities of daily living. Gerontologist 1969; 9: 179-86. [PubMed][CrossRef]

16. Lyketsos CG, Galik E, Steele C et al. The General Medical Health Rating: a bedside global rating of medical comorbidity in patients with dementia. J Am Geriatr Soc 1999; 47: 487-91. [PubMed][CrossRef]

17. Hermens ML, Adèr HJ, van Hout HP et al. Administering the MADRS by telephone or face-to-face: a validity study. Ann Gen Psychiatry 2006; 5:3. [PubMed][CrossRef]

18. Newkirk LA, Kim JM, Thompson JM et al. Validation of a 26-point telephone version of the MiniMental State Examination. J Geriatr Psychiatry Neurol 2004; 17: 81-7. [PubMed][CrossRef]

19. Jorm AF. A short form of the Informant Questionnaire on Cognitive Decline in the Elderly 
(IQCODE): development and cross-validation. Psychol Med 1994; 24: 145-53. [PubMed][CrossRef]

20. Hughes CP, Berg L, Danziger WL et al. A new clinical scale for the staging of dementia. Br J Psychiatry 1982; 140: 566-72. [PubMed][CrossRef]

21. Rush AJ, Kraemer HC, Sackeim HA et al. Report by the ACNP Task Force on response and remission in major depressive disorder. Neuropsychopharmacology 2006; 31: 1841-53. [PubMed][CrossRef]

22. Barca ML, Engedal K, Selbaek G. A reliability and validity study of the cornell scale among elderly inpatients, using various clinical criteria. Dement Geriatr Cogn Disord 2010; 29: 438-47. [PubMed][CrossRef]

23. Winblad B, Palmer K, Kivipelto M et al. Mild cognitive impairment-beyond controversies, towards a consensus: report of the International Working Group on Mild Cognitive Impairment. J Intern Med 2004; 256: 240-6. [PubMed][CrossRef]

24. Comijs HC, Nieuwesteeg J, Kok R et al. The two-year course of late-life depression; results from the Netherlands study of depression in older persons. BMC Psychiatry 2015; 15: 20. [PubMed][CrossRef]

25. Mirza SS, Wolters FJ, Swanson SA et al. 10-year trajectories of depressive symptoms and risk of dementia: a population-based study. Lancet Psychiatry 2016; 3: 628-35. [PubMed][CrossRef]

Publisert: 4. november 2019. Tidsskr Nor Legeforen. DOI: 10.4045/tidsskr.18.0968

Mottatt 16.12.2018, første revisjon innsendt 15.4.2019, godkjent 28.6.2019.

(C) Tidsskrift for Den norske legeforening 2020. Lastet ned fra tidsskriftet.no 